\title{
Questionnaire survey of urinary incontinence in women with cystic fibrosis
}

\author{
A Orr, R JMcVean, A K Webb, M E Dodd
}

Cystic fibrosis is an inherited disease characterised by the production of infected secretions, and it requires lifelong daily treatment by airway clearance. We knew that some women attending our clinic for adults with cystic fibrosis leaked urine when performing airway clearance or spirometry, but they were dismissive during discussion and were rarely forthcoming about the problem. This study was designed to determine the prevalence of urinary incontinence in women with cystic fibrosis, to establish the importance of the problem as perceived by the patients, and to identify those women who wanted help.

\section{Participants, methods, and results}

We invited women with cystic fibrosis who attended our clinic in the four month study period to complete an anonymous questionnaire. The questionnaire was self administered and semistructured, and it contained 15 items (see appendix on BMJ's website). The questions related to the severity, causes, and physical or social impact of leakage when the chest was "good" or "bad."

Overall, $75(90 \%)$ of our 83 registered women patients came to the clinic during the study period, and all of these completed the questionnaire. In total, 51 $(68 \%)$ patients reported leakage of urine occurring more than once or twice in the previous 12 months (table). Women were classified into six age groups; leakage was present in all groups (range 54-100\%), with no significant age trend $\left(\chi^{2}=1.1: \mathrm{P}=0.29\right)$. Of the 75 patients, $12(16 \%)$ had completed a pregnancy, but in six $(50 \%)$ of these leakage had occurred before the pregnancy. One woman was menopausal.

Leakage occurred only when the chest was "bad" in $14(27 \%)$ women, but in the remaining $37(73 \%)$ leakage

Symptoms, severity, and impact of urinary leakage in 51 women aged 16-52 years with cystic fibrosis. ${ }^{*}$ Values are numbers (percentages)

\begin{tabular}{lcc} 
& \multicolumn{2}{c}{ Chest } \\
\cline { 2 - 3 } & "Good" & "Bad" \\
\hline Symptoms causing leakage: & $30(59)$ & $48(94)$ \\
\hline Coughing & $23(45)$ & $25(49)$ \\
\hline Sneezing & $18(35)$ & $27(53)$ \\
\hline Laughing & $11(22)$ & $13(25)$ \\
\hline Full bladder & $9(18)$ & $18(35)$ \\
\hline Huffing & $4(8)$ & $10(20)$ \\
\hline Spirometry & $31(61)$ & \\
\hline Severity of leakage: & $10(20)$ & $25(39)$ \\
\hline Few drops & $7(14)$ & $12(24)$ \\
\hline Change of underwear & $5(10)$ & $13(25)$ \\
\hline Change pads & $4(8)$ & $11(22)$ \\
\hline Leakage to overclothes & 0 & $2(4)$ \\
\hline Leakage down legs & & \\
\hline Emptying whole bladder & $4(8)$ \\
\hline Impact of leakage: & $4(16)$ \\
\hline Airway clearance & $1(2)$ & $8(16)$ \\
\hline Physical activity & $8(16)$ \\
\hline Spirometry &
\end{tabular}

${ }^{\star}$ The remaining 24 women in the study reported no leakage. was not confined to periods of exacerbation. Coughing, sneezing, laughing, and spirometry were the major causes of leakage, which was worse for all causes when the chest was "bad." In eight $(16 \%)$ women, leakage affected the ability to perform airway clearance and spirometry. Overall, 15 (29\%) women reported the need to wear pads, $15(29 \%)$ were severely distressed by their incontinence, and 10 (20\%) had sought help previously. Reasons given for not seeking help included "not as serious as my chest disease" (23/51 (45\%) women) and "too embarrassed" (12 (24\%) women). A wish for treatment was expressed by 18 (35\%) women.

\section{Comment}

Urinary incontinence is common in women with cystic fibrosis. Our results show a prevalence of $68 \%$, which is higher than that in the normal population for all age groups. ${ }^{12}$ The prevalence of leakage in women over 35 was $80-100 \%$ for those with cystic fibrosis compared with $35 \%$ in a normal population ${ }^{1}$ and in women aged 16 -20 was $64 \%$ compared with $12.8 \%{ }^{3}$. The effect of urinary incontinence on patients' ability to perform airway clearance and spirometry has a clinical impact since these procedures are crucial to assessing and managing the pulmonary aspects of cystic fibrosis. The low number of women who wanted help for their reported leakage is reason for concern; once leakage occurs there is a chronic and progressive deterioration of the pelvic neuromuscular function. ${ }^{4}$ Patients considered the problem to be less serious than their chest disease, and they were too embarrassed to seek help. Many were severely distressed by their leakage, and the need to use pads-a means of concealing and coping with the problem-was greater than in an older population. ${ }^{2}$ Addressing this problem should become part of the routine management of cystic fibrosis in paediatric and adult centres. A practical and sensitive approach needs to be developed to evaluate this little recognised condition in women with cystic fibrosis who already have the burden of a multisystem disease with high morbidity and mortality.

We wish to thank the physiotherapy department of the Royal Brompton and Harefield NHS Trust for their contribution to the questionnaire.

Contributors: $\mathrm{AO}$ and $\mathrm{MD}$ participated in designing the study, analysing and interpreting the results, and writing the paper. RM participated in designing the study and analysing and interpreting the results. AKW participated in the critical revision of the paper. MD is the guarantor for the paper.

Funding: None.

Competing interests: None declared.

1 Thomas TM, Plymat KR, Blannin J, Meade TW. Prevalence of urinary incontinence. BMJ 1980:281:1243-5.

2 Dolan LM, Casson K, McDonald P, Ashe RG. Urinary incontinence in Northern Ireland: a prevalence study. BJU Int 1999;83:760-6.

3 Chiarelli P, Brown W, McElduff P. Leaking urine: prevalence and associated factors in Australian women. Neurourol Urodyn 1999;18:567-77.

4 Gunnarsson M, Mattiasson A. Female stress, urge, and mixed urinary incontinence are associated with a chronic and progressive pelvic floor/ vaginal neuromuscular disorder: an investigation of 317 healthy and incontinent women using vaginal surface electromyography. Neurourol Urodyn 1999;18:613-21.

(Accepted 30 March 2001)
Adult Cystic

Fibrosis Unit, North West Lung Centre, South Manchester University Hospitals Trust, Manchester

M23 9LT

A Orr

senior physiotherapist R J McVean

senior physiotherapist

A K Webb

professor of thoracic

medicine

M E Dodd

specialist

physiotherapy

clinician

Correspondence to: A Orr

alison.orr@smuht.

nwest.nhs.uk

BMJ 2001;322:1521

b) con

The questionnaire used in this study appears on the BMJ's website 